\title{
Plasmid instability when the hsp60 gene promoter is used to express the protective non-toxic fragment $B$ of the diphtheria toxin in recombinant BCG
}

\author{
Dilzamar V. Nascimento ${ }^{1}$, Odir A. Dellagostin'ㄹ, Raphael Hirata Jr. ${ }^{1}$, Geraldo M. B. Pereira ${ }^{1,3}$, \\ Ana Luiza Mattos-Guaraldi ${ }^{1}$, Geraldo R. Garcia Armôa ${ }^{3}$ \\ ${ }^{1}$ Faculdade de Ciências Médicas, Universidade do Estado do Rio de Janeiro, Rio de Janeiro, Brazil \\ ${ }^{2}$ Centro de Biotecnologia, Universidade Federal de Pelotas, Campus Universitário, Pelotas, Brazil \\ ${ }^{3}$ Instituto Oswaldo Cruz, Fundação Oswaldo Cruz, Rio de Janeiro, Brazil \\ Email: guaraldi@pq.cnpq.br, guaraldi@uerj.br
}

Received 30 August 2012; revised 1 March 2013; accepted 25 April 2013

Copyright (C) 2013 Dilzamar V. Nascimento et al. This is an open access article distributed under the Creative Commons Attribution License, which permits unrestricted use, distribution, and reproduction in any medium, provided the original work is properly cited.

\begin{abstract}
The genetic modification of the live attenuated $M y$ cobacterium bovis BCG to deliver a protective Corynebacterium diphtheriae antigen in vivo could be a safer and less costly alternative to the new and more expensive DTP vaccines available today, in particular to third world-countries. The stability of expression of heterologous antigens in BCG, however, is a major challenge to the use of live recombinant bacteria in vaccine development and appears to be dependent to a certain extent, on a genetic compatibility between the expression cassette within the plasmid construct and the mycobacterium host. In the quest for the best recombinant BCG transformant to express the $d t b$ gene of $C$. diphtheriae we generated two new rBCG strains by transforming the Moreau substrain of BCG with the mycobacterial expression vectors pUS973 and pUS977, each one carrying a different promoter to drive the expression of the target antigen. After transformation recombinant BCG clones were selected on Middlebrook 7H10 kanamycin Agar plates, expanded in Middlebrook 7H9 kanamycin Broth and analyzed by agarose gel electrophoresis and immunoblotting. rBCGs transformed with the construct carrying the weak $\boldsymbol{P}_{A N}$ promoter from $M$. paratuberculosis stably expressed the $d t b$ gene. Conversely, rBCGs transformed with the construct carrying the strong mycobacterium $h s p 60$ promoter were unstable and consequently unfit for the expression of the $C$. diphtheriae gene.
\end{abstract}

Keywords: BCG Vaccine; Recombinant BCG; Fragment B of Diphtheria Toxin; Anti-Diphtheria Vaccine

\section{INTRODUCTION}

Diphtheria, the classical disease caused by $C$. diphtheriae is an acute communicable infection of the upper respiratory tract that can be fatal $[1,2]$. Although the global incidence of diphtheria has been reduced dramatically as a result of increased vaccine coverage, infections by different biotypes of $C$. diphtheriae continue to be reported in many countries [3,4]. The diphtheria toxin (DT) is a polypeptide with a molecular weight of about 58,000 Daltons that is cleaved into two fragments to become active. The fragment A (DTA) with 193 amino acids is an enzyme that catalytically inactivates the ribosomal elongation factor- 2 of eukaryotic cells while the 342 amino acids long fragment B (DTB) recognizes and binds to specific receptors on the surface of most eukaryotic cells, facilitating the translocation of the fragment A across the membrane [5]. Despite the existence of a very good toxoid vaccine, diphtheria has not been eradicated yet. On the other hand, the current toxoid based vaccine presents risks to vaccinees associated to the production process. These risks include incomplete inactivation and the presence of reactor and unknown proteins generated during the inactivation process. For this reason the immunization against diphtheria has to be done with three doses to minimize adverse effects that could take place with a full single dose [6,7]. Adverse side reactions of that kind could be easily avoided by purification of the current vaccine. However, the purification of the diphtheria toxoid would increase the cost of production considerably.

The Bacillus of Calmette-Guérin (BCG), a live attenuated substrain of $M$. bovis obtained almost a century ago, is currently the only vaccine licensed against TB world wide. The recombinant BCG approach developed 
on top of it emerged in the late 80 's as a creative technology for in vivo delivery of protective antigens and brought a new hope for the development of low cost multivalent vaccines $[8,9]$. In this context, a genetically modified BCG strain expressing a relevant diphtheria antigen could be a safer alternative to the current classic vaccine used against diphtheria in places where BCG is mandatory. Nevertheless, the stability of the expression of heterologous antigens in BCG is still a major issue and perhaps one of the most important obstacles to the use of this technology in vaccine development. In fact there are several reports in the literature showing that genetic rearrangements lead to the disruption of the expression of heterologous genes or promoters in mycobacteria [10-14]. In this paper, we report our first results over the expression of the $C$. diphtheriae gene $d t b_{\mathrm{PW} 8}$ by the $M$. bovis BCG substrain Moreau used in Brazil to produce the vaccine against TB, modified by the transformation with distinct plasmid vectors, pUS973 and pUS977, to generate two new recombinant strains in which the expression of the target gene is driven by a strong (hsp60) or a weak $\left(P_{A N}\right)$ mycobacterium promoter. A comparison of the structural stability of plasmid constructs used to transform BCGs with constructs rescued after transformation and growth of the two rBCGs in culture medium are presented.

\section{MATERIALS AND METHODS}

\subsection{Bacterial Strains and Media}

The toxigenic strain of $C$. diphtheriae Park Williams 8 (ATCC 13812) was used as the source of genomic DNA, while the Escherichia coli DH5 $\alpha$ strain was used for amplification of all plasmid vectors. $C$. diphtheriae was grown in Brain Heart Infusion broth and E. coli in LuriaBertani broth or agar plates with or without ampicillin $(75 \mu \mathrm{g} / \mathrm{mL}$ ). The BCG vaccine (M. bovis BCG, Moreau substrain) was provided by the Brazilian National producer Fundação Athaulpho de Paiva in Rio de Janeiro, RJ [15] and was typically grown at $37^{\circ} \mathrm{C}$ in Middlebrook $7 \mathrm{H} 9$ or $7 \mathrm{H} 10$ medium supplemented with ADC (Difco Laboratories) plus kanamycin $25 \mu \mathrm{g} / \mathrm{mL}$, when needed.

\subsection{Construction of Mycobacterial Expression Vectors Carrying the dtb Gene}

The DNA fragment corresponding to the $d t b_{\mathrm{PW} 8}$ gene was amplified from the $C$. diphtheriae genomic DNA by Polymerase Chain Reaction (PCR) using primers $d t b \mathrm{~F}$ (5'CGTCTAGAAGGTAGCTCATTGTC3') and $d t b \mathrm{R}$ (5'GCTCTAGACCCCACTACCTTTC3') designed from the sequence encoding the diphtheria toxin, GenBank accession code K01722 [16]. The PCR reaction was performed in the Gene Amp PCR System 2400 thermo cycler (Perkin Elmer) with 30 cycles of 5 minutes de- naturation at $94^{\circ} \mathrm{C}, 1.5$ minutes annealing at $55^{\circ} \mathrm{C}$ and 2 minutes extension at $50^{\circ} \mathrm{C}$. The PCR product was analyzed in agarose gel and the $1051 \mathrm{bp}$ amplicon band corresponding to the size of the $d t b_{\mathrm{PW} 8}$ DNA was purified, digested with $X b a \mathrm{I}$ and then cloned into the same site of the expression vectors pUS973 and pUS977 [17, 18], giving rise to pUS973dt $b_{\mathrm{PW} 8}$ and pUS977dt $b_{\mathrm{PW} 8}$ constructs, respectively. The identity of the DNA inserts was confirmed by DNA sequencing.

\subsection{Transformation of BCG, Analysis of rBCG Clones for Expression of $d t b_{\mathrm{PW} 8}$ and Plasmid Integrity}

The Moreau BCG was transformed with pUS973dt $b_{\mathrm{PW}}$ or pUS977 $d t b_{\mathrm{PW} 8}$, or with an empty plasmid, by electroporation. In order to do this BCG was grown to an optical density of $600 \mathrm{~nm}$ in Middelbrook 7H9 broth, centrifuged twice at $4000 \times \mathrm{g}$ for 10 minutes and resuspended to $1 / 20$ of its original volume in $10 \%$ glycerol. Further, 200 microliters of BCG were mixed with each plasmid DNA construct $(1-2 \mu \mathrm{g})$ in a pre-chilled $0.2 \mathrm{~cm}$ electroporation cuvette (Bio-Rad) and transformation was performed using a Gene Pulser apparatus (Bio-Rad) at $2.5 \mathrm{kV}, 1000 \Omega$ and $25 \mu \mathrm{F}$ [19]. Recombinant BCG clones were selected after $14-21$ days of incubation at $37^{\circ} \mathrm{C}$ on Middlebrook $7 \mathrm{H} 10$ agar plates containing kanamycin, expanded in Middlebrook 7H9 broth with kanamycin at $37^{\circ} \mathrm{C}$ and $2.0 \mathrm{~mL}$ aliquots of each culture were harvested at mid-log growth phase, lysed and subjected to $12 \%$ SDS-PAGE. After separation in the SDS gel, proteins were electrotransferred to nitrocellulose membranes (Bio-Rad, Hercules, California) and subjected to immunoblotting analyses to detect the expression of the DTB protein using mice anti-toxoid polyclonal antibodies (1:5000 dilution), according to standard procedures described in our previews studies [16]. Recombinant BCG clones were also analyzed with regards to plasmid integrity to confirm the presence of the $d t b_{\mathrm{PW} 8}$ gene by restriction analyses with $X b a \mathrm{I}$ of plasmids recovered from $\mathrm{rBCG}$ expressing $d t b_{\mathrm{PW}}$, or not [20].

\section{RESULTS}

A 1051 bp long DNA fragment, named $d t b_{\text {Pw8 }}$, necessary to build the expression vectors used in this study to modify BCG was successfully amplified by PCR from the genome of the $C$. diphtheriae $\mathrm{PW} 8$ vaccine strain, using specific primers designed to do it as referred above. The identity of the $d t b_{\mathrm{PW} 8}$ gene was confirmed by DNA sequencing and analysis of similarity against the sequence of DT deposited in the GenBank. The gene $d t b$ was further cloned into the extrachromossomal mycobacterial expression vectors pUS973 and pUS977 generating constructs pUS973dt $b_{\mathrm{PW} 8}$ and pUS977dt $b_{\mathrm{PW} 8}$, respec- 
tively, and these were used to transform BCG. The two new $\mathrm{rBCG}$ strains resulting from transformation were evaluated in terms of their capacity to express $\mathrm{rDTB}_{\mathrm{PW} 8}$ in vitro. The only difference between vectors pUS973 and pUS977 is the promoter sequence used to drive the expression of the foreign gene. The pUS973 vector carries the strong constitutive hsp60 promoter from $M$. tuberculosis, while pUS977 carries the $P_{A N}$ promoter from $M$. paratuberculosis. The expression of DTB in rBCG was evaluated by immunoblotting assays using polyclonal antibodies against the diphtheria toxoid. As predicted, a band of the expected size for DTB, $40 \mathrm{kDa}$, was recognized in lysates of rBCGpUS973dt $b_{\mathrm{PW} 8}$ or rBCGpUS977 $d t b_{\text {Pw8 }}$ subjected to immunoblot analysis. The level of expression of $\mathrm{rDTB}_{\mathrm{PW} 8}$ observed in $\mathrm{BCG}$ transformed with pUS973dt $b_{\mathrm{PW} 8}$ was similar to $\mathrm{BCG}$ transformed with pUS977 $d t b_{\mathrm{PW} 8}$ (Figures 1(a) and (b)). Mycobacteria and corynebacteria have a common ancestry and may as well share antigens. This fact possibly contributed to the fact that the use of polyclonal antibodies in the immunoblotting assays led to the visualization of non-specific rest bands in both non-transformed and transformed BCG. In order to verify the structural stability of the recombinant plasmids, selected BCG transformants were subjected to two successive passages in 7H9 Middlelbrook medium supplemented with kanamycin. Subsequently, plasmid DNA was recovered by electroduction into E. coli [20]. Several colonies were selected and the purified plasmid DNA was digested with $X b a \mathrm{I}$. Electrophoresis of the digested DNA revealed that most BCG clones transformed with pUS973dt $b_{\mathrm{PW} 8}$ had undergone mutations (Figure 2(a)), whereas none of the pUS977dtb $b_{\mathrm{PW} 8}$ clones showed alteration in the structure of the plasmid (Figure 2(b)). In fact, a few constructs from rBCGpUS973dt $b_{\mathrm{PW} 8}$ (Figure 2(a), lanes 2-5) lost the $X b a \mathrm{I}$ site and part of the plasmid DNA since they exhibited a lower molecular mass when compared to the original vector (lanes 8-10) used as control. Also, other constructs recovered from clones of the same rBCGpUS973dt $b_{\text {PW8 }}$ strain apparently lost part of their

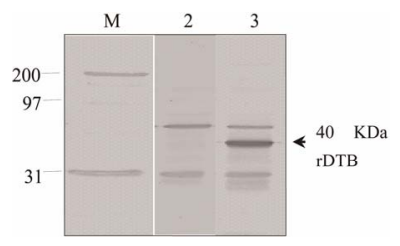

(a)

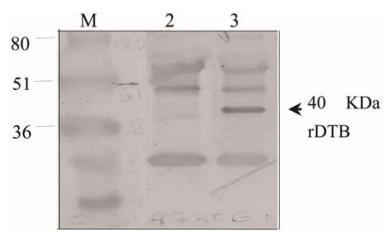

(b)
Figure 1. Immunoblotting analysis of rBCGpUS973 $d t b_{\mathrm{PW} 8}$ and rBCGpUS977dtb $b_{\mathrm{PW} 8}$ cell lysates. (a) lane M: molecular weight markers; lane 2: non-modified BCG lysate; lane 3: rBCGpUS973dt $b_{\text {PW8 }}$ lysate; (b) lane M: molecular weight markers; lane 2: non-modified BCG; lane 3: rBCGpUS977dtb $b_{\text {PW8 }}$ lysate. The arrows at the right of gels indicate a band of the expected size for rDTB.

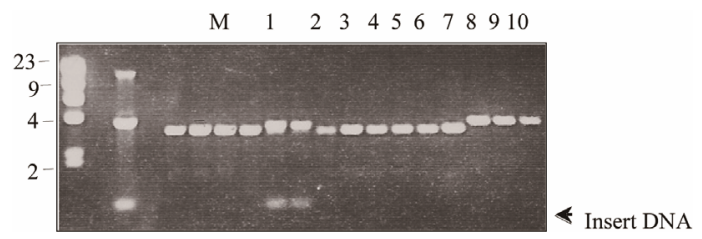

(a)

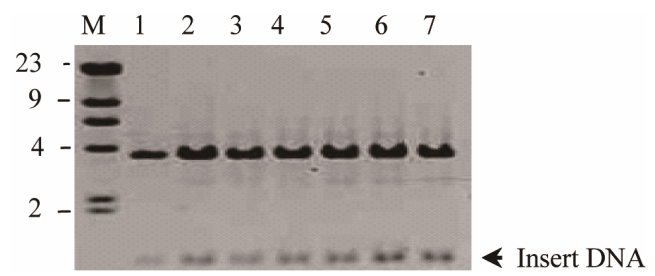

(b)

Figure 2. Agarose gel electrophoresis analysis of pUS973dt $b_{\mathrm{PW} 8}$ and pUS977dt $b_{\mathrm{PW} 8}$ constructs recovered from rBCGpUS973 $d t_{\text {PW8 }}$ and rBCGpUS977$d t b_{\text {PW8 }}$ clones after digestion with $X b a \mathrm{I}$. (a) lane M: DNA markers ( $\lambda$ HindIII); lane 1: pUS973dt $b_{\text {Pw8 }}$. The top band corresponded to an artifact resulting of the non-digested plasmid applied in excess on the gel. the two lower bands corresponded to the linearized pUS973 plasmid (middle band) and the excised insert (lowest band); lanes 2-7: pUS973dtb $b_{\mathrm{PW} 8}$ clones; lanes 8-10: empty pUS973; (b) lane M: DNA

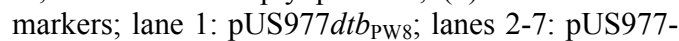
$d t b_{\mathrm{PW} 8}$ clones. the arrows at the right of gels indicate the DNA insert liberated after digestion.

DNA in spite of having released the insert (lanes 6 and 7). Indeed, the instability of constructs based on the $h s p 60$ promoter is not new. It has been shown that mutations may occur as a result of modifications of the promoter or insert sequences [13]. What is new is that it also occurs with the $d t b_{\mathrm{PW} 8}$ gene from $C$. diphththeriae.

\section{DISCUSSION AND CONCLUSIONS}

The genetic modification of the BCG vaccine as an approach to the development of new multivalent vaccines has been actively pursued ever since it was proposed in 1989 [8] and has been the focus of our research over the last years [21-28]. BCG is a powerful candidate to a multivalent vaccine platform. We successfully constructed a new and stable rBCG strain able to express the non-toxic fragment $\mathrm{B}$ of the $C$. diphthteria toxin by genetically modifying the Moreau substrain of BCG used in the production of the vaccine against TB in Brazil. Although a mutant of the DT, CRM197, has been expressed in BCG using the promoter pBlaf [29], this is the first clear demonstration that the safer B fragment of DT can be expressed and well tolerated by BCG. These are definitive conditions for the development of vaccine prototypes based on this technology since not every antigen is necessarily expressed or tolerated by BCG. Our best results came out with the BCG transformed with the 
pUS977dt $b_{\text {PW8 }}$ construct in which the expression of DTB is driven by the $P_{A N}$ promoter, a regulatory sequence derived from $M$. paratuberculosis. The $P_{A N}$ sequence, a weak mycobacterial promoter [18], has been successfully used by others for the expression of the $\alpha$-galactosidade of E. coli [30], the LacZ of E. coli [31], the Gp63 surface antigen of Leishmania [32], the Nef antigen of Simian Immunodeficiency Virus [33], the Nef, Gag, Env antigens of Simian Immunodeficiency Virus [34], the S1 subunit of the Bordetella pertussis toxin [24], the hepatitis B surface antigens [35] and the LipL32 antigen of Leptospira interrogans [28]. In our study all $\mathrm{rBCGpUS977dtb_{ \textrm {PW } }}$ clones stably expressed significant amounts of DTB while $\mathrm{rBCGpUS973} d t b_{\mathrm{PW} 8}$ clones were unstable and, consequently, unsuitable for DTB expression. Both $h s p 60$ and $P_{A N}$ are constitutive mycobacterial promoters and have been widely used in recombinant BCG studies [18, $35,36]$. The reason for the instability of rBCGs transformed with the pUS973 construct designed with the stronger $h s p 60$ promoter is not yet clear and was not the objective of this study. However, it is known that the expression of heterologous antigens in recombinant BCG essentially imposes a metabolic burden with an unpredictable outcome and also, although not frequent in mycobacteria, the modification of the $h s p 60$ promoter may result from a recombination event between host and plasmid sequences [11]. Consequently, the foreign gene expression driven by the $h s p 60$ promoter is not always feasible in BCG [11,37]. The hsp 60 promoter has a much stronger activity when compared to the $P_{A N}$ promoter and this may result in a more stressful metabolic scenario for the host cell, which in turn may select point mutations or deletions in the $h s p 60$ promoter region disrupting the expression of the heterologous protein. In fact, there may be a lethal level of synthesis of the foreign protein followed by selection of mutants with deletion in the promoter region immediately after induction of the $h s p 60$ promoter in the transformed host [13]. Based on the preliminary data presented here we believe that the recombinant $\mathrm{BCG}$ expressing the $\mathrm{rDTB}_{\mathrm{Pw}}$ polypeptide under the $P_{A N}$ promoter can be further exploited for the development of a vaccine prototype as an alternative for the current vaccine against diphtheria. We showed that $P_{A N}$ promoter was expressed continuously in vitro during intracellular growth of $M$. bovis BCG, and basically all rBCGpUS977 $d t b_{\mathrm{PW} 8}$ clones stably expressed the nontoxic fragment $\mathrm{B}$ of the diphtheria toxin. On the other hand, the pUS973, a similar expression vector based on the use of a heat shock protein promoter (hsp60) was highly unstable and inadequate for expression of the $d t b_{\mathrm{PW} 8}$ gene.

\section{ACKNOWLEDGEMENTS}

This study was carried out in partial fulfillment of the requirements of a
PhD thesis for Dilzamar V. Nascimento, Faculdade de Ciências Médicas (PGCM), Universidade do Estado do Rio de Janeiro, Rio de Janeiro, RJ, Brazil. Research supported by Bio-Manguinhos/FIOCRUZ, PAPES II/FIOCRUZ, FAPERJ, CNPq, CAPES, Programa de Núcleo de Excelência (PRONEX/MCT/CNPq).

\section{REFERENCES}

[1] Kimura, Y., Watanabe, Y., Suga, N., Suzuki. N., Maeda, K., Suzuki, K., Kitagawa, W., Miura, N., Morita, Y. and Imai, I. (2011) Acute peritonitis due to Corynebacterium ulcerans in a patient receiving continuous ambulatory peritoneal dialysis: A case report and literature review. Clinical and Experimental Nephrology, 15, 171-174. doi:10.1007/s10157-010-0346-4

[2] Viguetti, S.V., Pacheco L.G.C., Santos, L.S., Soares, S.C., Bolt, F., Baldwin, A., Dowson, C.G., Rosso, M.L., Guiso, N., Miyoshi, A., Hirata Jr., R., Mattos-Guaraldi, A.L. and Azevedo, V. (2012) Multilocus sequence types of invasive Corynebacterium diphtheriae isolated in Rio de Janeiro urban area, Brazil. Epidemiology and Infection, 140, 617-620. doi:10.1017/S0950268811000963

[3] Mattos-Guaraldi, A.L., Moreira, L.O., Damasco, P.V. and Hirata Jr., R. (2003) Diphtheria remains a threat to health in developing world-An overview. Memórias do Instituto Osvaldo Cruz, 98, 987-993. doi:10.1590/S0074-02762003000800001

[4] Wagner, K.S., White, J.M., Neal, S., Crowcroft, N.S., Kupreviciene, N., Paberza, R., Lucenko, I., Joks, U., Akbas, E., Alexandrou-Athanassoulis, H., Detcheva, A., Vuopio, J., von Hunolstein, C., Murphy, P.G., Andrews, N., Members of the Diphtheria Surveillance Network (DIPNET) and Efstratiou, A. (2011) Screening for Corynebacterium diphtheriae and Corynebacterium ulcerans in patients with upper respiratory tract infections 2007 2008: A multicentre European study. Clinical Microbiology and Infection, 17, 519-525. doi:10.1111/j.1469-0691.2010.03269.x

[5] Pappenheimer Jr., A.M. (1977) Diphtheria toxin. Annual Review of Biochemistry, 46, 69-94. doi:10.1146/annurev.bi.46.070177.000441

[6] Uchida, T. (1983) Diphtheria toxin. Pharmacology Therapeutics, 19, 107-122. doi:10.1016/0163-7258(82)90043-2

[7] Johnson, V.G. and Nicholls, P.J. (1994) Identification of a single amino acid substitution in the diphtheria toxin A chain of CRM 228 responsible for the loss of enzymatic activity. Journal Bacteriology, 176, 4766-4769.

[8] Jacobs Jr., W.R., Snapper, S.B., Lugosi, L., Jekkel, A., Melton, R.E., Kieser, T. and Bloom, B.R. (1989) Development of genetic systems for mycobacteria. ACTA Leprologica, 1, 203-207.

[9] Bastos, R.G., Borsuk S., Seixas, F.K. and Dellagostin, A.O. (2009) Recombinant Mycobacterium bovis BCG. Vaccine, 27, 6495-6503. doi:10.1016/j.vaccine.2009.08.044

[10] Summers, D.K. (1993) Stability of genetic material in prokaryotes. Biologicals, 21, 91-93. 
doi:10.1006/biol.1993.1053

[11] Haeseleer, F. (1994) Structural instability of recombinant plasmids in mycobacteria. Research in Microbiology, 145, 683-687. doi:10.1016/0923-2508(94)90040-X

[12] Kumar, D. (1998) Genetic rearrangements leading to disruption of heterologous gene expression in mycobacteria: An observation with Escherichia-coli beta-galactosidase in Mycobacterium smegmatis and its implication in vaccine development. Vaccine, 16, 1212-1215. doi:10.1016/S0264-410X(98)80121-7

[13] Al-Zarouni, M. and Dale J.W. (2002) Expression of foreign genes in Mycobacterium bovis BCG strains using different promoters reveals instability of the $h s p 60$ promoter for expression of foreign genes in Mycobacterium bovis BCG strains. Tuberculosis (Edinb), 82, 283-291. doi:10.1054/tube.2002.0374

[14] Joseph, J., Lloris, R.F., Pezzat, E., Saubi, N., Cardona, P. J., Mothe, B. and Gatell, J. M. (2010) Molecular characterization of heterologous HIV-1 gp 120 gene expression disruption in Mycobacterium bovis BCG host strain: A critical issue for engineering mycobacterial based vaccine vectors. Journal of Biomedicine Biotechnology, 2010, 110. doi:10.1155/2010/357370

[15] Benévolo-de-Andrade, T.C., Monteiro-Maia, R., Cosgrove, C. and Castello-Branco, L.R. (2005) BCG Moreau Rio de Janeiro an oral vaccine against tuberculosis review. Memórias do Instituto Oswaldo Cruz, 100, 459465. doi:10.1590/S0074-02762005000500002

[16] Nascimento, D.V., Lemes, E.M.B., Queiroz, J.L.S., Silva Jr., J.G.S., Nascimento, H.J., Silva, E.D., Hirata Jr., R., Dias, A.A.S.O, Santos, C.S., Pereira, G.M.B., MattosGuaraldi, A.L. and Armoa, G.R.G. (2010) Expression and purification of The immunogenically active fragment B of the Park Williams 8 Corynebacterium diphtheriae strain toxin. Brazilian Journal of Medical and Biological Research, 43, 409-521.

doi:10.1590/S0100-879X2010007500032

[17] da Cruz, F.W., McBride, A.J.A., Conceição, F.R., Dale, J.W., McFadden, J. and Dellagostin, O.A. (2002). Expression of the B-cell and T-cell epitopes of the Rabies virus nucleoprotein in Mycobacterium bovis BCG and induction of a humoral response in mice. Vaccine, 20, 731-736. doi:10.1016/S0264-410X(01)00414-5

[18] Medeiros, M.A., Dellagostin, O.A., Armôa, G.R., Degrave, W.M., De Mendonça-Lima, L., Lopes, M.Q., Costa, J.F., Mcfadden, J. and McIntosh, D. (2002) Comparative evaluation of Mycobacterium vaccae as a surrogate cloning host for use in the study of mycobacterial genetics. Microbiology, 148, 1999-2009.

[19] Parish, T. and Stoker, N.G. (1995). Electroporation of mycobacteria. Methods Molecular Biology, 1, 237-252.

[20] Baulard, A., Jourdan, C., Mercenier, A. and Locht, C. (1992) Rapid Mycobacterial plasmid analysis by electroduction between Mycobacterium spp. and Escherichia coli. Nucleic Acids Research, 20, 4105. doi:10.1093/nar/20.15.4105

[21] Dellagostin, O.A., Wall, S., Norman, E. O'Shaughnessy, T., Dale, J.W. and McFadden, J. (1993) Construction and use of integrative vectors to express foreign antigens in mycobacteria. Molecular Microbiology, 10, 983-993. doi:10.1111/j.1365-2958.1993.tb00970.x

[22] Dellagostin, O.A, Esposito, G., Eales, L.J., Dale, J.W. and McFadden, J. (1995) Activity of mycobacterial promoters during intracellular and extracellular growth. $\mathrm{Mi}$ crobiology, 141, 1785-1792.

doi:10.1099/13500872-141-8-1785

[23] Varaldo, P.B., Leite, L.C., Dias, W.O., Miyaji, E.N., Torres, F.I., Gebara, V.C., Armôa, G.R., Campos, A.S., Winter, N., Gicquel, B., Vilar, M.M., MacFadden, J., Almeida, M.S., Tendler, M. and McIntosh, D. (2004) Recombinant Mycobacterium bovis BCG expressing the Sm14 antigen of Schistosoma mansoni protects mice from cercarial challenge. Infection and Immunity, 72, 3336-3343. doi:10.1128/IAI.72.6.3336-3343.2004

[24] Medeiros, M.A., Armôa, G.R., Dellagostin, O.A. and McIntosh, D. (2005) Induction of humoral immunity in response to immunization with recombinant Mycobacterium bovis $\mathrm{BCG}$ expressing the $\mathrm{S} 1$ subunit of Bordetella pertussis toxin. Canadian Journal of Microbiology, 51, 1015-1020. doi:10.1139/w05-095

[25] Michelon, A., Conceição, F. R., Binsfeld, P.C., da Cunha, C.W., Moreira, A.N., Argondizzo, A.P., McIntosh, D., Armôa, G.R., Campos, A.S., Faber, M., Mcfadden, J. and Dellagostin, O.A. (2006) Immunogenicity of Mycobacterium bovis BCG expressing Anaplasma marginale MSP1a antigen. Vaccine, 11, 6332-6339.

doi:10.1016/j.vaccine.2006.05.028

[26] Varaldo, P.B., Miyaji, E.N., Vilar, M.M., Campos, A.S.D., Dias, W.O. Armôa, G.R., Tendler, M., Leite, L.C. and McIntosh, D. (2006) Mycobacteria codon optimization of the gene encoding the Sm14 antigen of Schistossoma mansoni in recombinant Mycobacterium bovis Bacille Calmette-Guerin enhances expression but not protection against cercarial challenge in mice. FEMS Immunology and Medical Microbiology, 48, 132-139. doi:10.1111/j.1574-695X.2006.00133.x

[27] Santangelo, M.P., McIntosh, D., Bigi, F., Armôa, G.R., Campos, A.S.D., Ruybal, P., Dellagostin, O.A., McFadden, J., Mendum, T., Gicquel, B., Winter, N., Farber, M. and Cataldi, A. (2007) Mycobacterium bovis BCG as a delivery system for the RAP-1 antigen from Babesia bovis. Vaccine, 25, 1104-1113. doi:10.1016/j.vaccine.2006.09.069

[28] Seixas, F.K., Silva, E.F., Hartwig, D.D., Cerqueira, G.M., Amaral, M., Fagundes, Q., Dossa, R.G. and Dellagostin, O.A. (2007) Recombinant Mycobacterium bovis BCG expressing the LipL32 antigen of Leptospira interrogans protects hamsters from challenge. Vaccine, 26, 88-95. doi:10.1016/j.vaccine.2007.10.052

[29] Miyaji, E.N., Mazzantini, R.P., Dias, W.O., Nascimento, A.L., Marcovistz, R., Matos, D.S., Raw, I., Winter, N., Gicquel, B., Rappuoli, R. and Leite, L.C. (2001) Induction of neutralizing antibodies against diphtheria toxin by priming with recombinant CRM197, a mutant diphtheria toxin. Infection and Immunity, 69, 869-874. doi:10.1128/IAI.69.2.869-874.2001

[30] Murray A., Winter, N., Lagranderie, M., Hill, D.F., Rauzier, J., Timm, J., Leclerc, C., Gheorghiu, K.M. and Gicquel, B. (1992) Expression of Escherichia coli beta ga- 
lactosidase in Mycobacterium bovis BCG using an expression system isolated from Mycobacterium paratuberculosis which induced humoral and cellular immune responses. Molecular Microbiology, 6, 3331-3342. doi:10.1111/j.1365-2958.1992.tb02201.x

[31] Lagranderie, M., Murray, A., Gicquel, B., Leclerc, C. and Gheorghiu M. (1993) Oral immunization with recombiant BCG induces cellular and humoral immune responses against the foreing antigen. Vaccine, 11, 1283-1290. doi:10.1016/0264-410X(93)90096-G

[32] Abdelhak, S., Louzir, H., Timm, J., Blel, L., Benlasfar, Z., Lagranderie, M., Gheorghiu, M., Dellagi, K. and Gicquel, B. (1995) Recombinant BCG expressing the leishmania surface antigen $\mathrm{Gp} 63$ induces protective immunity against Leishmania major infection in BALB/C mice. Microbiology, 141, 1585-1592. doi:10.1099/13500872-141-7-1585

[33] Winter, N., Lagranderie, M., Gangloff, S., Leclerc, C., Gheorghiu, M. and Gicquel, B. (1995). Recombinant BCG strains expressing the SIVmac251 nef gene Induce proliferative and CTL responses against nef synthetic peptides in mice. Vaccine, 13, 471-478. doi:10.1016/0264-410X(94)00001-4

[34] Mederle, I., Le Grand, R., Vaslin, B., Badell, E., Vingert,
B. and Dormont, G. (2003) Mucosal administration of three recombinant Mycobacterium bovis BCG-SIVmac251 strains to cynomolgus macaques induces rectal IgAs and boosts systemic cellular immune responses that are primed by intradermal vaccination. Vaccine, 21, 41534166. doi:10.1016/S0264-410X(03)00537-1

[35] Rezende, C.A.F., De Moraes, M.T.B., Matos, D.C.S., McIntosh, D. and Armôa, G.R.G. (2005) Humoral response and genetic stability of recombinant BCG expressing hepatitis B surface antigens. Journal of Virological Methods, 125, 1-9. doi:10.1016/i.jviromet.2004.11.026

[36] Stover, C.K., Bansal, G.P., Hanson, M.S., Burlein, J.E., Palaszynski, S.R. and Young, J.F. (1993) Protective immunity elicited by recombinant bacilli Calmette-Guérin (BCG) expressing outer surface protein A (OspA) lipoprotein: A candidate lyme disease vaccine. Journal Experimental Medicine, 178, 197-209. doi:10.1084/jem.178.1.197

[37] Fan, X.-Y., Ma, H., Guo, J., Li, Z.-M., Cheng, Z.-H., Guo, S.-Q. and Zhao, G.-P. (2009) A novel differential expression system for gene modulation in mycobacteria. Plasmid, 61, 39-46. doi:10.1016/j.plasmid.2008.09.002 